\title{
Atwood in Numbers: A Numerical Approach Comparing the Illustrations in Bones and Murder and The Tent
}

\begin{abstract}
This paper offers analyses of the semantic interrelations between illustrations and written text in short stories from two flash fiction collections by Margaret Atwood: Bones and Murder (1994) and The Tent (2006). The analyses are based on the technical, generic, and thematic features of the illustrations, on the influences traceable in both illustrations and texts, and on the set of defined multimodal interrelations. The results of the analyses are expressed numerically and comparatively.
\end{abstract}

Keywords: flash fiction; Margaret Atwood; illustrations; multimodality

\section{Atwood v številkah: Numerični pristop $k$ primerjavi ilustracij $\mathrm{v}$ Bones and Murder in The Tent}

\section{POVZETEK}

Prispevek analizira semantične povezave med ilustracijami in pisanim besedilom v kratkih zgodbah iz dveh zbirk flash fikcije avtorice Margaret Atwood: Bones and Murder (1994) in The Tent (2006). Analize temeljijo na tehničnih, splošnih in tematskih značilnostih ilustracij, na vplivih, ki jih je mogoče zaznati tako pri ilustracijah kot tudi besedilih, in na vrsti definiranih multimodalnih medpovezav. Rezultati teh analiz so prikazani numerično in primerjalno.

Ključne besede: flash fikcija; Margaret Atwood; ilustracije; multimodalnost 


\section{Introduction}

The two major flash fiction ${ }^{1}$ collections by Margaret Atwood, Bones and Murder (1994) and The Tent (2006), were published within a 12-to 23-year interval. However, they share a substantial number of similarities that can be roughly categorized into three main groups: 1. Generic determination. Both are multimodal collections of short stories, some of which contain illustrations, and both collections also contain generically hybridized (poetry) and shape texts. ${ }^{3}$ 2. Both collections share stylistic similarities: short, brisk sentences are prevalent, a seemingly simple style provides a world of hidden meanings and connotations, and most of the stories, even paragraphs within stories, are semantically and stylistically framed by skilful and often humorous/ironic punchlines. 3 . The collections are thematically closely related. The stories in both collections deal primarily with the lives of female characters, their relations with other people and, even more importantly, with themselves; furthermore, the stories in both collections discuss the themes of existence, consciousness and artistic creation (artistic creation being the pivotal theme in The Tent). The range and importance of the similarities between these two collections point towards the conclusion that The Tent could easily be regarded as a logical sequel to the earlier collection.

Atwood provided her own illustrations, and the drawings in both collections share an abundance of features that can be categorized as follows:

1. Technique; the illustrations in both collections are freehand, black ink drawings;

2. Positioning; the illustrations are inserted into texts without framing, occupying a whole printed page; in both collections, only a small number of the stories are illustrated;

3. Presentation; both collections feature an introductory illustration that in a way anticipates the textual and the visual content of each collection;

4. Authorship; all illustrations in both collections are created by Margaret Atwood;

5. Style and artistic influences; the illustrations in both collections share a remarkable number of stylistic features and reveal a set of mutual artistic influences, ranging from ancient and classical art to the art of Secession;

6. Content; the illustrations in both collections depict similar motifs, to mention only the three most striking shared features: female characters, faces in profile, human bodies hybridized with those of animals and plants;

7. Visual and verbal interrelations; in both collections illustrations and texts form similar semantic bonds, which then leads to production of new layers of meaning which I call the third entity of meaning. ${ }^{4}$ This term is meant to define the meanings

Though this term became popular after Margaret Atwood published Bones and Murder, it is fitting for her stories. See also Gadpaille (2018) on the classification of Atwood's short pieces as slipstream fiction.

2 Some of the stories in Bones and Murders were first published in the collection Murder in the Dark in 1983; also, in some editions, the title is Good Bones and Simple Murder. For the sake of simplicity, this article will refer to Good Bones.

For the most part, again for the sake of simplicity, I use "texts" to refer to the written text, and "illustrations" to refer to Atwood's drawings.

4 As stated in my doctoral dissertation, "Visual and Verbal Interrelations in Canadian Short Fiction" $(2018,3)$. 
and potential interpretations of verbal and visual elements that are constructed by multimodal unity, rather than being dependent on the verbal or visual element alone.

Although the similarities between texts, illustrations, and their interrelations in both collections are numerous, there are important differences between the literary usage of the verbal and the visual in Bones and Murder and The Tent. These differences may point to a technical and thematic shift by Atwood that is essential for understanding these collections of flash fiction. In this paper I focus on the visual content in the collections by analysing, categorizing, and explaining differences between illustrations, their function in texts and multimodal interrelations between illustrations and texts.

\section{Theory and Methodology}

Little has been written about the interrelations between the verbal and visual in multimodal short fiction, especially in Canadian texts. In order to establish theoretical grounds for research in multimodal short prose, one must often rely on similar works written on multimodal novels. Hallet states:

[...] visual elements are not actually illustrations in the traditional sense, but part of the narrative world produced by the narrator and directly woven into the narrative discourse by the device of drawing upon them continuously in ekphrastic passages. (Hallet 2009, 133)

Here Hallet notes one essential feature of texts and illustrations in multimodal literature: when placed in multimodal interrelations, texts and illustrations redefine each other and transform their meanings. The result is a redistribution of meaning between and throughout the different modes. In that way, the visual becomes an important carrier of narrative meaning, while the verbal becomes semantically inseparable from the visual. In Hallet's functions of multimodality, the visual elements in such multimodal texts take an active role in constructing plots, creating characters and characters' world-making, in framing narration, in narrative bridging, ${ }^{5}$ and in constructing 'possible worlds,' that is in the creation of derivative meanings based on the amalgam of meanings provided by both the verbal and the visual texts. Atwood's flash fiction constitutes a postmodern literature where clues provided to the reader for the understanding of the texts are scarce, and the semantics of each text is stretched almost to the point of breaking. There is also some semantic detachment between Atwood's illustrations and the verbal texts (a feature that Hallet could hardly note in a lengthy genre like a traditional novel), which leads to her text showing very few or no ekphrastic elements.

What Hallet describes as 'possible worlds' is of central importance for my research in multimodal short prose:

It is neither the written verbal mode nor any of the other modes on its own that constitutes the story or builds the storyworld. Nor is it simply a matter of 'dialogue' between a verbal text and visual images. Rather, it is the complex interplay between

These are instances when authors of texts deliberately give up textual narration and apply the persuasive power of illustrations to tell a part of the story instead of texts. 
different semiotic modes, generic forms, and ways of conceiving and making sense of the world that eventually constitutes novelistic narration. (Hallet 2009, 148)

Here Hallet notes another essential feature of texts and illustrations in multimodal literature: in a complex process of semantic transformations, different modes in multimodal literature inevitably produce new meanings and connotations which were not previously offered independently by either mode. However, this process goes beyond the production of novelistic (literary) narration, characters and settings; it modifies the semiotic basis of the verbal and the textual, and it provides almost endless possibilities for interpretation. Multimodal short prose modifies the meaning of the verbal and visual to the point where their original meanings becomes practically indistinguishable, and the bulk of interpretation relies on the third meaning, which is produced by the interrelation of the two modes but is not independently conveyed by either. ${ }^{6}$ The term 'possible worlds' only partly conveys that complexity. For that reason, I propose the term the third entity of meaning. This term is useful in analyses when both the texts and illustrations are produced by the same author, which is the case in these two Atwood collections.

It is now necessary to define the types and features of those semantic interrelations in multimodal short prose which allow the production of the third entity of meaning. During my doctoral research, I devised the following typology of multimodal interrelations in illustrated short prose:

1. Complementation: meanings of a text and meanings (and devices expressing meanings) of illustrations complement each other in various aspects of narration (ideas, style/genre/form);

2. Reflection: meanings of a text and meanings (and devices expressing meanings) of illustrations reflect certain patterns or individual elements of narration (ideas, style/ genre/form) across the border of the two media;

3. Focusing: meanings of a text and meanings (and devices expressing meanings) of illustrations focus on one or several patterns of narration, ideas, style/genre/form which they share across the borders of the two media;

4. Bridging: meanings of a text provide the basis for the understanding of certain features of an illustration which the illustration does not present, and, vice versa, meanings of illustrations bridge meanings indicated by but not directly present in the text;

5. Cohesion: an idea proposed by a visual multimodal element provides textual unity to the pertinent verbal text; this relation usually goes only one way: a picture does not necessarily need this type of unity because of what Sillars calls "the immediate experiential force of the illustration" (2004, 76-77);

6. Contrast: opposition/contrast between verbal and visual is formal or epochal, or the opposition/contrast is expressed through the verbal and visual narratives; this is often used to produce irony, and reinforce epiphany in short multimodal prose;

In that sense, I would compare the semantic transformations in non-multimodal prose to creating a new sort of meaning using already related types of meaning; I compare the semantic transformations in multimodal prose to genetic modification of meaning, which might include hybridization with the elements of unrelated breeds of meaning but also with elements of different species of meaning. 
7. Exclusion: the verbal and the visual acknowledge mutual existence by exclusion, producing absence where we would expect presence as the only source of multimodality.

Most texts in Atwood's illustrated flash fiction feature several types of multimodal interrelations. Here I will consider only the two most prominent multimodal interrelations evident in each text/illustration.

In considering Atwood's short prose, I will focus mostly on the illustrations, i.e. on the semantic, formal, and stylistic differences between illustrations in Bones and Murder and The Tent.

\section{Illustrations in Bones and Murder and The Tent: A Comparison}

Atwood's collection Bones and Murder consists of thirty-five short stories, ten of which are illustrated by Atwood. The formation of this collection of flash fiction took 11 years. Atwood first published Murder in the Dark in 1983, and some of the stories from that collection appeared in the 1992 collection Good Bones. Atwood, perhaps, saw this collection as an ongoing project (which extends to and includes the creation of The Tent); hence, Good Bones was republished in 1994 as Good Bones and Simple Murders (or just as Bones and Murder), a collection combining the stories from the 1983 and 1992 collections.

Bones and Murder features an introductory illustration, an image of a (detective) hat, which openly but deceitfully anticipates the thematic world of the collection - deceitfully, because no real crime is depicted in the stories (the only crime suggested being writing itself). The texts are semantic puzzles, and it is up to the reader to make sense of them. Consequently, the reader becomes the detective, and the detective hat is offered to him/her as guidance and encouragement in the tricky world of Atwood's multimodal prose.

The positioning of illustrations follows no discernible pattern; illustrated stories are randomly distributed throughout the collection. Within the texts, illustrations occupy one whole printing page with no visual framing to the drawings. All the illustrations are freehand drawings done in black ink.

The illustrations in Bones and Murder offer a relatively wide thematic range. They feature mostly female characters, animals, plants, and landscape, but placed in a variety of situations and interactions. There are two features in the depiction of human characters which stand out: all faces are drawn in profile, and human bodies and features are often hybridized with those of animals and plants. Special attention should be given to the analyses of Atwood's visual implementation of the letters of the alphabet, clothing, and mythology in her illustrations. It is exactly her usage of the letters of the alphabet which later became the prominent technique and a salient element in the crucial illustrations for The Tent.

Various artistic influences can be detected in Atwood's illustrations for Bones and Murder. Firstly, her drawing style shows clear features of children's art, which is not a surprise, considering her engagement in children's literature (such as her 1990 For the Birds, illustrated 
by Shelly Tanaka, and her 1995 Princess Prunella and the Purple Peanut). The childlike playfulness of her illustrations, when adjusted for adult readers, unavoidably reflects some features of naïve art. The most prominent artistic influence in Atwood's illustrations (and in her intertextual fiction which can be classified as writing back) is the influence of classical antiquity. Her depictions of profiles with enlarged, almond-shaped eyes, unmistakably point towards Egyptian, Mesopotamian, Ancient Greek, and Persian Art. The hairstyles of Atwood's characters resemble those in Ancient Greek and Roman art. This is confirmed with her drawings of clothing. Atwood's illustrations are also rich in elements of classical mythology, symbolism (i.e. the use of ouroboros images), and beliefs. For 20th-century influences, there is a strong streak of Secession in Atwood's illustrations, and sparse elements of popular culture (i.e. gestalt figures ${ }^{7}$ ).

Besides these artistic influences, the illustrations to Bones and Murder show elements of nonaesthetic, that is, scientific illustration. The most prominent branches of science present in Atwood's illustrations in the collection are medicine and zoology.

In the following sections I will analyse each illustration in the collection based on the aforementioned elements and features.

The introductory image of the hat functions as the illustration to the first story in the collection, "Murder in the Dark":

You can say: the murderer is the writer, the detective is the reader, the victim is the book. Or perhaps, the murderer is the writer, the detective is the critic, and the victim is the reader. In that case the book would be the total mise en scène, including the lamp that was accidentally tipped over and broken. But really it's more fun just to play the game. (Atwood 1995, 3)

Here Atwood ironically writes about the process of creation, consummation, and even appreciation of the literary work. As is common in Atwood's work, roles can change. They can be bestowed upon anyone involved; metaphorically speaking, anyone can become a detective, a killer or a victim. The ironic comment is contained in Atwood's advice not to think too much and to just play the game. The illustration of the hat embodies the dominant multimodal interrelations of complementation and focusing with "Murder in the Dark." It also provides cohesion to the other texts in the collection. An introductory image is featured not only in Bones and Murders, but also in The Tent.

The next illustration in the collection can be found in the story "The Little Red Hen Tells All." The illustration features a hybridized body of a hen with a female face, a round eye and a breast sitting on a large egg, much bigger than the hen itself. The overall impression of the illustration strongly points towards naïve art. In the yolk of the egg there are letters of the alphabet. There is a bold reference to writing and literary creation in both the illustration and

Gestalt images, also known as figure-ground drawings, are images that depict repeated or reflected forms. They are often positioned in such a way as to provide a recognizable shape for their background. Form and background are often differentiated and opposed by white and black colouring. Gestalt images are an ancient method of illustration, but Margaret Atwood uses that method in a contemporary manner. 
the verbal text. The illustration of the hen mainly embodies the multimodal interrelations of complementation and reflection with the texts that it illustrates.

Significantly, the letters of the alphabet in the hen illustration are trapped within the yolk of the egg, recalling the way letters appear in the shape of the tent in the introductory illustration to The Tent. All this reaffirms my argument that The Tent is a logical and thematically/technically more focused sequel to Bones and Murder.

The next illustration in Bones and Murder appears in "Women's Novels." The illustration features a female character in a background landscape. The female body is hybridized, as her body and arms seem to be swirls of wind. Her body is also a remnant of a snake's body, but simultaneously of octopuses and spiders (both mentioned in the text in the description of the female character). Her face is in profile with an Atwoodian almond eye. As in the hen illustration, the female figure in this illustration features a salient human breast. In the background there is a black Moon (a symbol of both lunacy and women), and a hill with three black silhouettes of trees on the top. The silhouettes of the trees bear a strong resemblance to the spiky brushes used in the tails of the fox demons that guard the letters of the alphabet in the illustrations to The Tent. The story deals with the relations of women and men, their points of view, habits and decisions, and the illustration focuses only on the female character. However, what is expressed by the illustration shows that the dominant multimodal interrelations are those of complementation and reflection, while the interrelation of focusing would be the next most prominent feature.

The illustration to the story "Stump Hunting" stands out in comparison to others because it depicts a male character in an everyday situation. The face is shown in profile, and the character, wearing a baseball cap, is sitting in a boat on a lake, fishing. Behind him is a floating stump, above him two clouds. An important feature of this illustration is duality; the realistic world of the fishing man is divided with a line, which is also the surface of the water, from a surreal underwater world, which reveals that the stump is an ominous looking monster, which will most likely threaten either the fisherman or the fish under his boat. A realistic looking fish is preparing to take the bait, which adds to the irony. Both the story and the illustration deal with important issues of human existence: the need for domination, the duality of perception, and the ambiguity of reality. The story and the illustration do not follow each other literally, as they tell the story in a significantly different way, contrasting each other to emphasize the ironic effect. "Stump Hunting" thus contains two opposed but complementary jokes told in two different modes. The verbal and the visual in this story operate mostly through the multimodal interrelations of complementation and contrast.

Together with the illustration for "Women's Novels," the illustration accompanying the story "Let Us Now Praise Stupid Women" became the centrepiece of the collection, the iconic images of Bones and Murder. Indeed, there is a semantic and formal connection between these images. The illustration in "Let Us Now Praise Stupid Women" features a naked female figure with her face and an almond-shaped eye shown in profile. Again, the body is hybridized; the entire lower body, from the hips down, is a serpent. Numerous serpents also form the female character's hair, with clear reference to the myth of Medusa. In her right hand, the woman holds an apple, which is possibly a reference to the biblical story of Eve, and in her left hand 
a letter $a$, the first letter of the alphabet, another reference to writing. The Medusa and Eve references point towards the title of the story. The fact that the word paper in the story can be connected with the image of living in a paper tent or house in The Tent, and that the letter $A$ is featured both in this illustration and in "Impenetrable Forest" in The Tent suggests the direct semantic relation between the two collections of flash fiction. The verbal text and the illustration in "Let Us Now Praise Stupid Women" do not formally follow each other; rather, they reflect the main shared ideas. The second-most important multimodal interrelation between the text and the illustration is focusing, namely, on two main points of narration: the letter $a$ (symbolizing writing, creation) and the apple (symbolizing the sin of creativity).

"The Female Body" features an ouroboros-like image of a large pumpkin (which is a reference to folk/naïve art) that contains a naked female body, which again features prominent breasts, with a face in profile, an almond-shaped eye, and distinctive hair. The woman's belly is shown opened in the manner of medical atlases, revealing the influence of medical illustration. The influence of science is traceable in the text as well, where a set of reflections on nature and the use of the female body is rendered in an ironic, quasi-scientific style. The extended position of her hands is similar to the illustration for "Let Us Now Praise Stupid Women" and echoes depictions of dance in classical antiquity. In the belly of the woman, we can see the image repeated: it is the same woman, just without a pumpkin. The belly of the smaller woman is also open for us to see, and it features a tiny pumpkin (which might suggest both continuation - ouroboros, or the ending of the cycle). This image suggests that the woman is pregnant with herself, a concept that features symbolically in the verbal text. Taking into consideration the importance of the fairy-tale pumpkin in the semantics and wording of the story, and that only the illustration focuses on the image of the pumpkin, I conclude that the predominant multimodal interrelations between the illustration and the text are cohesion and focusing.

Hybridised female figures appear again in the illustration to "Cold-Blooded". There are four female faces, only one en-face, the others in profile, with the usual almond-shaped eyes. The en-face figure making eye-contact with the observer is reminiscent of Medusa. Only the heads are human; their bodies belong to sea creatures. The sea floor is also featured, with the foot of the mollusc visible to the observer. The image shows a strong influence from illustrations in scientific books from the field of zoology. The hybridization of humans and animals in a quasi-scientific image achieves an ironic effect, and irony is the dominant feature of this story as well. However, the plot has little to do with the motifs in the illustration. The semantics of the illustration contrast with the verbal narrative and reflects only certain of its ideas. The dominant multimodal interrelations between the illustration and the text in this case are contrast and reflection.

As in other short pieces, "Alien Territory" offers no plot. It is, rather, a set of observations on the depersonalization of the human body. The illustration features a circle with strong sexual connotations (possibly one of the reproductive organs, which is then semantically connected to the pumpkin in "The Female Body"). Within the circle are two faces in profile, created as gestalt figures. The faces feature almond-shaped eyes and could be a female and a male kissing. The story mentions Bluebeard (an allusion not observable in the illustration), and 
Freud's primal scene theory, which has, in a bold interpretation, influenced the illustration. The dominant multimodal interrelations between illustration and verbal text in this short story are reflection and cohesion.

"An Angel" contains an illustration extending the concept in the little red hen illustration: a female person sitting on an oval shape. In this case, the woman is adorned with angel wings and her face is hidden by a black circle. Her oval seat can be seen as either an egg, a female breast or an eye. Within the oval is the blurred figure of a skull. Beneath the oval there are flames similar to those in The Tent. The verbal text and the illustration show several similar semantic features and reflected meanings; hence, they mainly embody the multimodal interrelations of complementation and reflection.

"Death Scenes" stands out from other images in Good Bones because it features only a black flowering plant, without human characters. The whole body of the plant is shown, from the flower to the root (a possible trace of the influence of scientific illustration). The texture of the flower seems scaly, while the texture of the leaves is like that of flesh, suggestive of hybridisation. The root of the flower, in the form of a bulb, continues Atwood's preoccupation with the symbolism of the womb, egg, birth, and motherhood. Similar to "Let Us Now Praise Stupid Women," the verbal text and illustration in "Death Scenes" reflect shared ideas and meanings, but the illustration clearly focuses on the symbolism of one image from the text, in this case, the black flower. The words of this story and the illustration reflect the dominant multimodal interrelations of reflection and focusing.

The last story, "Good Bones," features a gestalt image of landscape - a night scene of islands and the sea. Both islands and the sky are human faces in profile; the white and the black moons are closed eyes. Parts of human bodies are incorporated into the inanimate landscape elements. The illustration and the verbal text do not coincide in form and content at all. The interrelations between the two modes can be analysed mostly through the absence of formal connections and through important ideas shown independently by each mode. The verbal text of this story and the illustration constitute the only example of the dominant multimodal interrelations being exclusion and reflection in this collection of flash fiction.

The following table summarizes multiple features of all 11 illustrations in the collection Bones and Murder:

TABLE 1. Features of illustrations in Bones and Murder.

\begin{tabular}{|l|l|}
\hline Feature & Occurrence $\mathbf{x} / \mathbf{1 1},(\%)$ \\
\hline female figure(s) & $8 / 11,72 \%$ \\
\hline profiles & $8 / 11,72 \%$ \\
\hline almond eyes & $5 / 11,45 \%$ \\
\hline landscape & $3 / 11,27 \%$ \\
\hline hybridization & $10 / 11,91 \%$ \\
\hline alphabet & $2 / 11,18 \%$ \\
\hline children's art & $3 / 11,27 \%$ \\
\hline classical antiquity & $3 / 11,27 \%$ \\
\hline
\end{tabular}




\begin{tabular}{|l|l|}
\hline Secession & $2 / 11,18 \%$ \\
\hline mythology & $4 / 11,36 \%$ \\
\hline popular culture & $3 / 11,27 \%$ \\
\hline non-artistic & $2 / 11,18 \%$ \\
\hline multimodal interrelations & $\begin{array}{l}\text { Primary interrelations : } \\
\text { complementation } 5 / 11,45 \% \\
\text { reflection } 3 / 11,27 \% \\
\text { cohesion } 1 / 11,9 \% \\
\text { contrast } 1 / 11,9 \% \\
\text { exclusion } 1 / 11,9 \% \\
\text { Secondary interrelations: } \\
\text { reflection } 5 / 11,45 \% \\
\text { focusing } 4 / 11,36 \% \\
\text { cohesion } 1 / 11,9 \% \\
\text { contrast } 1 / 11,9 \%\end{array}$ \\
\hline
\end{tabular}

Turning to the second collection of flash fiction, we examine The Tent (2006), which contains 35 short stories divided into three sections. The illustrations are positioned symmetrically, two illustrations in each chapter. Moreover, The Tent contains an introductory image, making a total of 7 freehand illustrations in black ink, unframed and occupying one printing page. The genre of both verbal texts and illustrations in Bones and Murder and The Tent is similar: short stories and flash fiction (except for the two poems in The Tent). However, in The Tent Atwood turned more prominently towards classical art and mythology. The main themes of The Tent are writing/creation and the creator (along with existentialism, feminism and environmentalism, all of which are present in Bones and Murder as well), making the collection more self-referential but also slightly more thematically limited, or more focused than Bones and Murder. As a result, illustrations in The Tent seem to interact with their verbal texts in a slightly different manner.

The illustrations in The Tent feature mostly female characters with faces in profile. Atwood continues drawing almond-shaped eyes and hybridized bodies but in a slightly different way than in Bones and Murder. In the illustrations for The Tent, Atwood steps further away from naïve art and builds her images decisively on the influences of classical antiquity. Although the short stories in The Tent are replete with references to classical and biblical mythology, the illustrations never point directly to any of the mythical creatures or situations. Furthermore, the influence of Secession seems to be more prominent in The Tent, while the illustrations of Salome and the flagellant show visual elements of Victorian-era (or earlier) clothing, and medieval practices, respectively. One interesting feature of the illustrations in The Tent is the increased importance of clothing. The clothes are more detailed, more salient. They convey more symbolism that refers to the verbal text. Furthermore, the clothes do not disclose nudity, hence eliminating the elements of sexuality so prominent in Bones and Murder.

While the image of the hat in Bones and Murder is semantically inscrutable, ambiguous, and deceptive, the primary tent graphic is far clearer in its function and intention. The introductory illustration serves as a manifesto of the collection and prepares the reader for 
understanding the coming texts. Moreover, on the cover of the 2007 paperback edition, this graphic appears in red and black. Given that red and black are typical of Secession design, and given that the patterns in "Voice" and "Eating the Birds" also show Secession influence, this addition of colour constitutes a significant extension of meaning.

The tent illustration features two black demons with blank eyes and tails resembling flames (or trees). Their bodies look like hybridized foxes and rats. They are standing on a tentshaped pile of letters of the alphabet (or pyramid shaped; the first part of the Greek word pyramid is pyre, meaning fire, and that can be connected to the demons' flame-like tails; fire is usually a symbol of enlightenment, illumination, primal energy, the Creative Seed, and Divine Principle). Significantly, some letters in the pile form entire words. These legible words are eat, food, blow, said, zero, upon, once, did, book, lived, that, bad, there, was, blood, wilderness, killed, mind, and time. On closer inspection, we can group the words to form phrases and sentences, most notably "Once upon a time there was a...." The fact that the graphic tent includes words such as bad, blood, and killed is a direct thematic reference back to Bones and Murder. The demons seem to be choosing letters and words from the pile and gorging on them. In that way The Tent evokes Atwood's themes of eating, ${ }^{8}$ more precisely, devouring, and the migration of life energy from the victim to the one who consumes the victim, which is another semantic link between the two collections of flash fiction. Over the tent and the demons is a black sun surrounded by three clouds (both the sun and clouds are cartoonish and show the influence of children's art). The most persuasive conclusion is that this shape is a paper tent, one comprising pages of books with letters printed on them. The illusory protection from the wilderness of reality that the tent offers is the only protection that a writer or reader can hope for. This can be concluded from the following lines in "The Tent":

You are in the tent. It's vast and cold outside, very vast, very cold. It's a howling wilderness [...]. Many things are howling out there, in the howling wilderness. Many people are howling. (Atwood 2006, 143)

The trouble is, your tent is made of paper [...] You know you must write on the walls, on the paper walls, on the inside of your tent. (Atwood 2006, 144)

The tent illustration embodies the multimodal interrelations of complementation and cohesion with the story "The Tent" and with the other texts in the collection. In contrast to the illustration of the hat in Bones and Murder, focusing is not the dominant feature because the tent is a symbolic representation of a theme approached differently by all the stories in the collection.

"Impenetrable Forest," the first illustrated story, features an illustration that is emblematic of the collection The Tent and is in many ways semantically and formally related to the illustration in "Let Us Now Praise Stupid Women" in Bones and Murder. The illustration features a female figure with her face in profile. Below the waist, her body forms the letter $A$, which is an example of hybridization of the human body with the inanimate. The texture of the letter A is reminiscent of tissue cells or scales. She is wearing a corset, and there is a

Atwood readers will think first of her debut novel The Edible Woman (1969). 
triple ring in the shape of a letter $\mathrm{O}$ over her head, which recalls a saint's halo. Her hairstyle and clothing indicate a modern young woman. In her right hand she holds a large number 1 , which seems to radiate light from its top (in the story mentioned as the "light bulb"). The light is depicted by the letters $\mathrm{Y}, \mathrm{O}, \mathrm{I}, \mathrm{N}, \mathrm{Z}$, and at the centre of the light is the nowfamiliar round shape. The halo in the shape of an $\mathrm{O}$ and the stick in the shape of 1 connote holiness and magic, both being Atwoodian leitmotifs in relation to women. Compared to Bones and Murder, an interesting shift is observable in the illustrations for The Tent in the depiction of female characters: breasts are no longer a salient motif in the illustrations, and the almond-shaped eyes are larger and much more pronounced. This female figure stands on a slope covered with sparse vegetation hybridized with the letters of the alphabet (in the story described as the "forest"). The letters on the left read YT, W, B, and O (possibly forming the words two by), and on the right, we can see P, E, N, (forming the word pen; read as the phrase: two by pen, or two by a pen, if we consider the female figure's legs). Although many of the verbal and visual elements are complementary, the bulk of meaning is concentrated in the opposition between the meanings and allusions conveyed by the graphic and the words. This coincides with the narrative features of the story, which provides the juxtaposed (and opposed) realities of two people. The verbal text and the illustration thus fulfil the dominant multimodal interrelations of complementation and contrast.

Another female figure introduces the story "Voice," where the whole body and face are shown in profile. The shape of her hair coincides with the curly linear shapes emanating from her open mouth, which represent her voice. Above the representation of her voice, there is a small black heart (reminiscent of the shape of Salome's head in the story "Salome Was a Dancer"). It might be argued that both the hair and the curly voice shapes are subtly hybridized with the shapes of plants or the circulation of wind. The shape of her hair is reminiscent of the hair in the illustration for "The Female Body," and the movement of the wind reminds us of the illustration for "Women's Novels" in Bones and Murder. The woman's eyes are large and almond shaped, which, together with the shape of her skirt and its pattern, strongly suggests the influence of classical antiquity. The woman is walking up the stairs, which implies movement and effort. The story and its illustration closely follow and reaffirm each other in content and form, thus embodying the dominant multimodal interrelations of complementation and reflection.

"Salome Was a Dancer" also features an illustration of a female character, presumably of Salome. This is the only character in The Tent visually presented en-face. With her remarkably realistic face, Salome makes eye contact with the observer/reader. She has long hair that forms the shape of a heart around her face, and there is a plant growing from the top of her head, being an example of hybridization. Salome wears a black gown, shown in detail, similar to 19th-century women's formal dress. Her left hand is lowered next to her body, but in her right hand Salome holds an offering: a tray with her own severed head. The head on the tray is nearly identical to the other head, and the tray resembles the O-shapes used in Atwood's previous illustrations. Leaves, flowers, and stars from the plant are dripping from the tray. There is an interesting duality here; the figure's head and the plant might be symbolic representations of thoughts and emotions, while for the severed head, the plant leaves symbolize blood and death. Furthermore, this illustration is semantically related to 
the motif of offering in the illustrations from Bones and Murder: "Let Us Now Praise Stupid Women" and to "The Female Body." Offering (or opening up) could be regarded as the basis of every artistic creation. "Salome was a Dancer" and its illustration reflect each other semantically, but a more important aspect is their interrelation of contrast. The contrast is most evident in the triangular semantic relation between Salome the biblical myth, Salome from a Canadian town in the verbal text, and Salome in the illustration. The story and its illustration closely follow and reaffirm each other in content and form. Hence, they fulfil the dominant multimodal interrelations of contrast and reflection.

The verbal texts can be poetry, as in the case of "The Animals Reject Their Names and Things Return to Their Origins." The illustration features a kneeling, gender-neutral figure of a flagellant in a hooded, one-piece overall and with a whip in one hand. The whip is partially but clearly forming the hybridized silhouette of a bear. Above, there is a sun (or a moon) with an eye inscribed within it. The figure is depicted in profile, with the familiar almondshaped eye. The narrator in the poem is a bear, a symbol of nature, which rejects humanity in general, including humanity's impact and dominance. This highly ironic and bluntly environmental text mentions many elements from the illustration, but the dominant feature of the illustration is the contorted, torturous nature of human existence, expressed through the ironic idea of a person whipping him/herself with nature. In that sense, the poem and the illustration stand in the dominant multimodal interrelations of focusing and reflection.

The next illustrated text, "Eating the Birds," features two kneeling female figures depicted in profile. They face each other with open mouths. Both have almond-shaped eyes and clothing reminiscent of ancient cultures. Their arms, one partially covered with a scaly pattern, and the other with plant designs, are lowered next to their bodies in a position that is unusually passive for a situation in which the characters are in tense interaction. They are kneeling on a surface covered with ellipsoid forms, some blank, others with solid fill. The most striking feature of this illustration is that each character has a bird on the top of her head. The birds resemble the hen in Bones and Murder, with a possible influence of folk/naïve art. They have round eyes and open beaks, suggesting that they too are in interaction. One bird has a dark patch on her chest (alluding to emotion), and the other around her legs (alluding to passion). The illustration suggests complex interrelations between the birds and the women, where birds seem to have the upper hand, while the title of the story suggests that the birds will become prey. The illustration and verbal text of "Eating the Birds" reflect each other's meanings and form, which is reaffirmed by focusing on the bird motif. However, the illustration brings a plethora of new meanings to the text and provides a supplement to the narration which is not apparently verbalized. Hence, the text and the illustration mainly fulfil the multimodal interrelations of reflection and bridging.

The last illustrated story in the collection, "Nightingale," features highly hybridized depictions of two women with bird heads. They are both depicted in profile with almond-shaped eyes. The figure on the left is unnaturally attached to a stylized tree high above the ground, adding some irony to the notion of her being a bird. The figure on the right stands on the ground, facing the other figure, and their open beaks imply communication. The two female figures are very similar; they have comparable body shape, hair, body position, and gowns. The 
striking differences are the fact that the figure on the tree is considerably smaller and is wearing a white gown, while the larger figure on the ground wears a black gown. This duality implies that both figures represent the same person, and that the two figures are asymmetrical gestalt figures. Above the black figure there is a black moon, adding to the duality of the image. The interrelations between verbal and visual in "Nightingale" are similar to those in "Salome was a Dancer"; although the story offers an interaction between two mythical sisters, the bulk of the shared meaning is generated by the contrast between the mythological verbal narration and an illustration that appears to make minimal reference to the myth. Simultaneously, the meanings expressed by the story and the illustration closely follow and reaffirm each other in content and form. The verbal and visual in this example express the dominant multimodal interrelations of contrast and reflection.

The following table summarizes multiple features of all 7 illustrations in The Tent.

TABLE 2. Features of illustrations in The Tent.

\begin{tabular}{|l|l|}
\hline Feature & Occurrence $\mathbf{x} / 7,(\%)$ \\
\hline female figure(s) & $5 / 7,71 \%$ \\
\hline profiles & $6 / 7,85 \%$ \\
\hline almond eyes & $7 / 7,100 \%$ \\
\hline landscape & $3 / 7,43 \%$ \\
\hline hybridization & $7 / 7,100 \%$ \\
\hline alphabet & $2 / 7,28 \%$ \\
\hline children's art & $1 / 7,14 \%$ \\
\hline classical antiquity & $3 / 7,43 \%$ \\
\hline Secession & $3 / 7,43 \%$ \\
\hline mythology & $1 / 7,14 \%$ \\
\hline popular culture & $0 / 7,0 \%$ \\
\hline non-artistic & $0 / 7,0 \%$ \\
\hline multimodal interrelations & $\begin{array}{l}\text { Primary interrelations: } \\
\text { complementation 3/7, 43\% } \\
\text { contrast } 2 / 7,28 \% \\
\text { focusing } 1 / 7,14 \% \\
\text { reflection } 1 / 7,14 \% \\
\text { Secondary interrelations: }\end{array}$ \\
\hline $\begin{array}{l}\text { reflection } 4 / 7,57 \% \\
\text { contrast } 1 / 7,14 \% \\
\text { cohesion } 1 / 7,14 \% \\
\text { bridging } 1 / 7,14 \%\end{array}$ \\
\hline
\end{tabular}

\section{Conclusion}

In The Tent, female characters make up $71 \%$ of all characters, which is similar to Bones and Murder. But the visual depiction of females in The Tent is quite different: females are shown less physically, with no salient features of their femininity; their clothes are more detailed and 
salient; their eyes are more obviously inspired by ancient art, body hybridity is omnipresent but expressed much more subtly than in Bones and Murder. Furthermore, the illustrated female characters possess a sinister quality that is not as obvious in Bones and Murder. All but one character are shown in profile (85\%), and all the characters feature almond-shaped eyes. In contrast to Bones and Murder, the landscape features prominently in three illustrations in The Tent (43\%), which could reflect Atwood's focus on space and spatiality in the stories and illustrations.

A complex dichotomy of relations between the inside (of the tent) as opposed to the outside world (the wilderness) is one of the pivotal semantic features of the collection and provides further proof that The Tent is more thematically focused. All the characters and/or shapes in The Tent are hybridized, which is similar to Bones and Murder, but the hybridization is formally very different. In The Tent, hybridization is observable only in subtle details such as the pattern on clothes and the shape of hair/plants. Only the nightingale illustration features hybridization seen in Bones and Murder. Letters of the alphabet are represented more prominently than in Bones and Murder (28\%), but in this case, the statistics can be misleading. Letters are among the key features of the collection, and one of the narrative ideas/visual images that provide semantic cohesion for the entire collection. The letters in The Tent form not only words but entire sentences (yet another sign of the thematic focus on creative writing). While the influence of children's art is less than in Bones and Murder $(14 \%)$, the observable influence of classical antiquity is considerably stronger (43\%). This is due primarily to the more detailed depictions of characters' clothes and characters' uniformity (which points towards a higher level of semantic focus in the illustrations as well). The same could be said for the influence of the art of Secession (43\%), with one important note: the book cover for The Tent (Toronto: McClelland and Stewart Ltd., 2006) features the tent illustration in black, white and red, the colours emblematic of Secessionist design. In that sense, the art of Secession is an aesthetic manifesto of the collection.

The differences between Bones and Murder and The Tent are especially interesting in the comparison of the verbal and visual treatment of the mythological content. The stories in both collections, and especially those in The Tent, are replete with references to classical mythology and mythological characters and could be described as adaptations of or 'writing back' to mythological tales. But in The Tent, Atwood provides few illustration with unambiguous references to mythology: one of these is Salome, who, in an ironic twist, offers her own head on a tray instead of the head of John the Baptist. All the other illustrations are inspired by the ancient, mystical, and quasi-mythological, but cannot be brought into connection with any concrete mythological tale or character. The Salome illustration stands out as a relatively realistic illustration compared to others. Atwood has largely empowered her visual characters in The Tent to be independent of mainstream mythologies. Popular culture and the influence of non-aesthetic motifs are not present in The Tent. On the other hand, Salome's gown could be a ceremonial dress dating from the late medieval ages to the Victorian era, and the flagellant illustration provides us with a scene from the chambers of medieval castles.

The most prominent primary multimodal interrelation between the verbal and the visual in The Tent is complementation with $43 \%$ occurrences, followed by contrast $(28 \%)$. This 
strongly suggests that texts and illustrations in The Tent stand in looser semantic interrelation than in Bones and Murder. This is confirmed by the secondary multimodal interrelations, reflection (57\%), and contrast (14\%). Such a multimodal formation of meaning could be explained by the fact that The Tent is thematically more focused which, in turn, provided more semantic independence for the illustrations. It could also be why the introductory illustration of the tent provides more semantic cohesion to the entire collection, more than the hat in Bones and Murder. It functions as a graphic metatrope.

References in The Tent to the older collection of stories are numerous, making it highly intertextual. But The Tent is not only a continuation of the previous story; it is also the reformation and, arguably, enhancement of Bones and Murder. There is a significant shift in Atwood's approach observable in the comparative analysis. Firstly, The Tent is slightly more thematically focused and homogeneous, both in verbal and visual aspects. Secondly, that leads to a different quality of illustrations. The illustrations seem more concrete, more uniform, but simultaneously have a stronger impact on the reader/observer. And, thirdly, the loose multimodal interrelations in The Tent mirror the two previously stated claims. The illustrations and texts are mutually less complementary, and illustrations seem more semantically independent and artistically concrete.

\section{References}

Atwood, Margaret. 1995. Bones and Murder. London: Virago Press.

- 2006. The Tent. New York: Anchor Books.

Gadpaille, Michelle. 1999. "Visual Metatrope in Novels by Margaret Atwood and E. Annie Proulx." In Crossing Borders: interdisciplinary intercultural interaction, edited by Bernhard Kettemann and Georg Marko, 221-30. Tübingen: Gunter Narr Verlag.

—. 2018. "Sci-fi, Cli-fi or Speculative Fiction: Genre and Discourse in Margaret Atwood's 'Three Novels I Won't Write Soon.” ELOPE 15 (1): 17-28. https://doi.org/10.4312/elope.15.1.17-28.

Hallet, Wolfgang. 2009. "The Multimodal Novel: The Integration of Modes and Media in Novelistic Narration." In Narratology in the Age of Cross-Disciplinary Narrative Research, edited by Sandra Heinen and Roy Sommer, 129-53. Berlin-New York: Walter de Gruyter.

Löschnigg, Maria. 2014. The Contemporary Canadian Short Story in English: Continuity and Change. Trier: Wissenschaftlicher Verlag Trier.

Sillars, Stuart. 2004. "The Illustrated Short Story (Toward Typology)." In The Art of Brevity, Excursions in Short Fiction Theory and Analysis, edited by Per Winther, Jakob Lothe and Hans H. Skei, 70-80. Columbia: University of South Carolina Press.

Tutek, Nikola. 2018. "Visual and Verbal Interrelations in Canadian Short Fiction.” PhD diss., KarlFranzens University of Graz. http://unipub.uni-graz.at/download/pdf/2581. 